\title{
Maillard Reaction Products in Gluten-Free Bread Made from Raw and Roasted Buckwheat Flour
}

\author{
Maria Barbara Różańska ${ }^{1, * \mathbb{D}}$, Aleksander Siger ${ }^{2} \mathbb{D}$, Artur Szwengiel ${ }^{1} \mathbb{D}$, Krzysztof Dziedzic ${ }^{1}$ (D) \\ and Sylwia Mildner-Szkudlarz ${ }^{1, *(\mathbb{D})}$
}

1 Department of Food Technology of Plant Origin, Poznań University of Life Sciences, 31 Wojska Polskiego St., 60-624 Poznań, Poland; artur.szwengiel@up.poznan.pl (A.S.); krzysztof.dziedzic@up.poznan.pl (K.D.)

2 Department of Biochemistry and Food Analysis, Poznań University of Life Sciences, 60-623 Poznań, Poland; aleksander.siger@up.poznan.pl

* Correspondence: maria.rozanska@up.poznan.pl (M.B.R.); sylwia.mildner-szkudlarz@up.poznan.pl (S.M.-S.)

Citation: Różańska, M.B.; Siger, A.;

Szwengiel, A.; Dziedzic, K.;

Mildner-Szkudlarz, S. Maillard

Reaction Products in Gluten-Free

Bread Made from Raw and Roasted

Buckwheat Flour. Molecules 2021, 26,

1361. https://doi.org/10.3390/

molecules26051361

Academic Editor: Fernando M. Nunes

Received: 3 February 2021

Accepted: 1 March 2021

Published: 4 March 2021

Publisher's Note: MDPI stays neutral with regard to jurisdictional claims in published maps and institutional affiliations.

Copyright: (c) 2021 by the authors. Licensee MDPI, Basel, Switzerland. This article is an open access article distributed under the terms and conditions of the Creative Commons Attribution (CC BY) license (https:/ / creativecommons.org/licenses/by/ $4.0 /)$.
Abstract: The formation of Maillard reaction products (MRPs) in gluten-free bread made from roasted and raw buckwheat flour was examined. The levels of phenolic compounds such as flavonoids (catechin, naringenin, quercetin, rutin, and others) and phenolic acids (like 4-hydroxybenzoic, caffeic, dihydroxybenzoic, ferulic, gallic, syringic, vanillic, and p-coumaric) were measured using reversedphase ultra-high performance liquid chromatography-electrospray ionization mass spectrometry (RP-UHPLC-ESI-MS). Early and advanced Maillard reaction products were analyzed using HPLC, whereas spectrofluorimetric analysis was used to determine the levels of fluorescent intermediate compounds (FIC). The total levels of phenolic compounds were higher in the case of buckwheat bread prepared from roasted buckwheat flour (156 and $140 \mu \mathrm{g} / \mathrm{g}$ of crumb and crust, respectively). Rutin, gallic acid, and catechin were the most abundant phenolic compounds detected in roasted buckwheat bread. The roasting process resulted in significantly lower radical scavenging capacities (ABTS) of the total phenolics and flavonoids in the buckwheat bread. Taking into consideration these Maillard reaction products, we observed a significant increase in FIC level in roasted buckwheat crumb and crust (at about $40 \%$, and $38 \%$, respectively). At the same time, the $\mathrm{N} \varepsilon$-(carboxymethyl)lysine (CML) level did not change in roasted or raw buckwheat bread crumb, though in roasted buckwheat crust the concentration of CML increased by about $21 \%$.

Keywords: Maillard reaction products; furosine; fluorescent intermediate compounds; buckwheat bread; phenolic compounds; antioxidant activity

\section{Introduction}

Bread is one of the most popular cereal products in the world. In the last decade, an increase in interest in gluten-free (GF) products was observed. Numerous studies have being conducted to improve the quality of gluten-free (GF) bread [1] given its poor nutritional value (manifesting as insufficient levels of protein and the minerals $\mathrm{Ca}, \mathrm{Fe}$, $\mathrm{Mg}$, and $\mathrm{Zn}$ ) [2], poor aroma [3], and poor textural quality. Like other pseudocereals (e.g., amaranth, quinoa), buckwheat flour does not contain proteins with the ability to trigger the auto-immune response observed in celiac disease, and therefore can be used in the production of gluten-free bread [4]. Two types of buckwheat flour are commercially available with high variability in the composition of nutrients. The first is raw buckwheat flour, produced by using raw dehulled grains; the second is roasted buckwheat flour, which is obtained from buckwheat grains roasted at $130{ }^{\circ} \mathrm{C}$ under $5-6$ bars pressure for $1 \mathrm{~h}$, and then dehulled [5].

Raw buckwheat is usually processed into flour, but in Central and Eastern Europe the roasting process is also used to produce buckwheat groats (the whole grains sold as a food product). It is known that heat treatment of buckwheat grains alters their functional and nutritional properties and can modify their chemical composition, so different prohealth 
effects can be achieved by using different types of buckwheat groats and flour in food production. It should be highlighted that buckwheat is one of the best pseudocereal sources of phenolic compounds [4]. In raw and roasted common buckwheat (Fagopyrum esculentum), ferulic acid (8.94 and $5.78 \mathrm{mg} / \mathrm{kg})$, gallic acid $(2.84$ and $9.63 \mathrm{mg} / \mathrm{kg})$, rutin $(62.19$ and $43.21 \mathrm{mg} / \mathrm{kg}), p$-coumaric acid $(1.83$ and $1.78 \mathrm{mg} / \mathrm{kg})$, and quercetin $(26.95$ and $25.02 \mathrm{mg} / \mathrm{kg}$ ) have been found [6]. However, thermal processing of buckwheat leads to a notable reduction in its antioxidant capacity [6-8]. For example, Ma et al. [9] found that the total phenolic content of roasted buckwheat was statistically significantly higher than raw common buckwheat, but the opposite tendency was observed for the antioxidant activity of Tartary buckwheat.

Furthermore, the industrial thermal process can limit the negative effects of potential allergens and toxins in roasted groats and flours, which may also be the reason for the growing popularity of these raw materials [10]. Thermal processing causes the formation of end-products of Maillard reaction-melanoidins, which capable of increasing the antioxidative activity of food [11]. Notwithstanding, heat treatment during the roasting and baking process affects the formation of potentially harmful Maillard reaction compounds, such as acrylamide (ACR), hydroxymethylfurfural (HMF) furfural, and especially advanced glycation end products (AGE) e.g., Ne-(carboxymethyl)lysine) $[10,12,13]$. Numerous recent studies have been conducted on the antiglycation effect of polyphenolic compounds in the food matrices $[13,14]$, but there is a lack of information about Maillard reaction products (MRPs) formation in gluten-free bread made from buckwheat. Moreover, current research on the effect of heat treatment on buckwheat product mainly involves chemical composition changes and the Maillard reaction in single buckwheat type products, including buckwheat groats (kasha) and buckwheat flour [7-9].

The aim of this study was to assess the formation of Maillard reaction products during the production of gluten-free bread from raw and roasted buckwheat flour.

\section{Results and Discussion}

Results on the concentration of phenolic compounds in buckwheat bread are summarized in Table 1. In the case of crust and crumb of roasted buckwheat bread, the total phenolic compound content was $158 \%$ and $187 \%$ higher, respectively, than in bread produced with raw buckwheat flour. These findings can be related to the fact that the steaming processing in the production of roasted buckwheat flour led to a transfer of water-soluble substances from buckwheat husk to the grain [15]. Moreover, the degradation of the buckwheat grain cell membrane during the heat treatment could enhance the extractability of phenolic compounds from the bound fraction [16]. It should be highlighted that quercetin concentrations in raw buckwheat bread in the crumb and crust were 42-46 times higher than in the crumb and crust of the roasted buckwheat bread. These results are in line with those of Bhinder et al., who found that roasting Tartary buckwheat flour led to a decrease in quercetin content [10]. Previous studies confirmed that the thermal stability of quercetin, which is the aglycon of rutin, was lower than that of rutin, the most thermostable polyphenol $[9,10,17]$. It is likely that the activity of the enzymes that break down rutin during the heat treatment of buckwheat grain was inhibited in the production of roasted flour $[18,19]$. Hence, the lack of rutin-degrading enzymes in the roasted buckwheat flour during bread making did not lead to a decrease in rutin content in roasted buckwheat bread; this is unlike the situation with raw buckwheat bread, where rutin was not detected. The other abundant compounds in the roasted buckwheat bread, besides rutin, were gallic acid, dihydroxybenzoic acid, and catechin. The use of roasted buckwheat flour contributed to a significant increase in these compounds, suggesting that these compounds were liberated from bonded forms during heat treatment. Moreover, there were no significant differences in concentrations of gallic acid, dihydroxybenzoic acid, or catechin between the roasted buckwheat crumb and crust (Table 1). 
Table 1. Phenolic compounds and antioxidant activity of raw and roasted buckwheat bread.

\begin{tabular}{|c|c|c|c|c|}
\hline \multirow{2}{*}{$(\mu \mathrm{g} / \mathrm{g})$} & \multicolumn{2}{|c|}{ Raw Buckwheat Bread } & \multicolumn{2}{|c|}{ Roasted Buckwheat Bread } \\
\hline & Crumb & Crust & Crumb & Crust \\
\hline 1-O-Sinapoyl-beta-D-glucose & nd & $0.19 \pm 0.01^{b}$ & $0.25 \pm 0.03^{a, b}$ & $0.26 \pm 0.002^{a}$ \\
\hline 4-Hydroxybenzoate-O-glucoside & $4.97 \pm 0.47^{\mathrm{a}}$ & $3.26 \pm 0.06^{b}$ & nd & nd \\
\hline 4-Hydroxybenzoic acid & $0.73 \pm 0.02^{b}$ & $0.78 \pm 0.01^{\mathrm{b}}$ & $9.43 \pm 0.18^{a}$ & $8.70 \pm 0.45^{\mathrm{a}}$ \\
\hline Caffeic acid & $0.48 \pm 0.01^{\mathrm{a}}$ & $0.38 \pm 0.03^{\mathrm{b}}$ & $0.12 \pm 0.01^{\mathrm{c}}$ & $0.070 \pm 0.009^{c}$ \\
\hline Catechin & $3.98 \pm 0.01^{b}$ & $3.60 \pm 0.33^{b}$ & $22.08 \pm 1.08^{\mathrm{a}}$ & $20.12 \pm 0.63^{\mathrm{a}}$ \\
\hline Dihydroxybenzoic acid & nd & nd & $24.6 \pm 1.03^{\mathrm{a}}$ & $22.27 \pm 1.37^{\mathrm{a}}$ \\
\hline Ferulic acid & nd & nd & $0.15 \pm 0.009^{\mathrm{a}}$ & $0.17 \pm 0.001^{\mathrm{a}}$ \\
\hline Gallic acid & $1.47 \pm 0.13^{b}$ & $1.68 \pm 0.05^{b}$ & $25.46 \pm 0.08^{\mathrm{a}}$ & $23.61 \pm 1.07^{\mathrm{a}}$ \\
\hline Naringenin & nd & nd & $0.09 \pm 0.01^{\mathrm{a}}$ & $0.07 \pm 0.01^{\mathrm{a}}$ \\
\hline Quercetin & $40.42 \pm 0.89^{\mathrm{a}}$ & $41.75 \pm 1.7^{\mathrm{a}}$ & $0.96 \pm 0.11^{b}$ & $0.9 \pm 0.014^{b}$ \\
\hline Quercetin $3 \beta$-D-rutinoside (rutin) & nd & nd & $62.52 \pm 0.9^{\mathrm{a}}$ & $52.41 \pm 1.25^{b}$ \\
\hline Syringic acid & $2.12 \pm 0.05^{b}$ & $2.25 \pm 0.09^{b}$ & $7.77 \pm 0.22^{a}$ & $8.41 \pm 0.22^{a}$ \\
\hline Vanillic acid & nd & nd & $2.26 \pm 0.15^{\mathrm{a}}$ & $2.5 \pm 0.23^{a}$ \\
\hline$p$-coumaric acid & $0.26 \pm 0.03^{b}$ & $0.23 \pm 0.07^{b}$ & $0.38 \pm 0.015^{\mathrm{a}}$ & $0.370 \pm 0.012^{\mathrm{a}}$ \\
\hline Total & $54.43 \pm 0.89^{\mathrm{c}}$ & $54.12 \pm 1.70^{\mathrm{c}}$ & $156.07 \pm 0.22^{\mathrm{a}}$ & $139.86 \pm 1.37^{b}$ \\
\hline Antioxidant activity (TEAC/g sample) & $3.65 \pm 0.04^{b}$ & $4.40 \pm 0.03^{\mathrm{a}}$ & $2.80 \pm 0.03^{c}$ & $2.97 \pm 0.09^{c}$ \\
\hline
\end{tabular}

Results are the mean \pm standard deviation. Different letters $(\mathrm{a}, \mathrm{b}, \mathrm{c})$ in the same row mean significant differences $(p<0.05)$. nd-not detected.

The antioxidant activity of raw and roasted buckwheat bread is given in Table 1 . The parameters of the roasting process, particularly temperature and time, are known to affect the antioxidant activity of various food products. Interestingly, the roasting process led to a significant decrease $(p<0.05)$ in the antioxidant activity of buckwheat bread. Zieliński et al. showed a loss of antioxidant activity in common buckwheat (Fagopyrum esculentum) after roasting at $160{ }^{\circ} \mathrm{C}$ [7]. The results presented here are in agreement with those of Sensoy et al. [20], who found that roasting dark buckwheat flour at $200{ }^{\circ} \mathrm{C}$ for $10 \mathrm{~min}$ led to an increase in nonpolar and polar compounds, but decreased their antioxidant activity. Besides phenolics, other compounds such as proteins can contribute to the measured antioxidant activity of buckwheat products [21]. Furthermore, according to Horáková, the prooxidant properties of flavonoids depend on their concentration [22]. It is therefore likely that a high flavonoid content in roasted buckwheat bread will also involve a pro-oxidative effect. Some authors have proposed that phenolic compounds, as well as ascorbic acid, are able to participate in the Maillard reaction, leading to a decrease in their antioxidant activity [23]. According to the literature, it is suggested that the reduction in antioxidant activity due to the roasting process may also be due to the formation of MRPs with prooxidant properties during the early stages of browning [24].

Research in recent years has focused on the inhibitory effect of phenolic compounds on the formation of MRPs $[25,26]$. Moreover, the antiglycation activity of phenolic compounds is usually associated with their antioxidant efficiency in the following decreasing order: quercetin $>$ gallic acid $>$ catechin $>$ ferulic acid [27].

Table 2 shows the MRPs formed in bread crumb and crust formulated with roasted and raw buckwheat flour. Due to the high proportions of fat (10\%) and sugar $(9 \%)$, along with the yeast, it is difficult to compare the level of MRPs in buckwheat samples to other bakery products.

Furosine (FUR), formed during acid hydrolysis of Amadori rearrangement products (ARPs) from lysine, has been proposed as an indicator of the early stage Maillard reaction. It has been reported that FUR is an unsuitable marker for the effect of heat treatment during baking, as it rapidly changes into advanced MRPs [28]. However, the FUR content of buckwheat bread crumb and crust could be useful for understanding the Maillard reaction mechanism in the model buckwheat bread. The levels of FUR were significantly reduced ( $\sim 91 \%$ ) in buckwheat roasted crumb and crust (6.34 and $8.73 \mathrm{mg} / \mathrm{kg}$, respectively) compared to raw buckwheat bread (71.56 and $117.56 \mathrm{mg} / \mathrm{kg}$ for crumb and crust, respectively). This could be explained by the fact that the buckwheat roasting process favors the 
formation of more advanced, fluorescent, cross-linking MRPs in the bread. Similarly, an increase in intermediary and advanced MRPs (fluorescent intermediate compounds (FIC) and $\mathrm{N} \epsilon$-carboxymethyl lysine (CML) level) was reported by Wronkowska et al. [8], who looked at changes in the formation of MRPs induced by buckwheat groats roasted at $160{ }^{\circ} \mathrm{C}$ for 30, 40, and $50 \mathrm{~min}$. Çelik and Gökmen did not detect FUR in whole and refined wheat bread crust-like samples heated at $200{ }^{\circ} \mathrm{C}$ for over $15 \mathrm{~min}$, which confirms the instability of FUR under heat treatment [29]. It is worth noting that in this study FUR levels in raw buckwheat bread crust (Table 2) were higher than $>100 \mathrm{mg} / \mathrm{kg}$. In contrast, Çelik and Gökmen found that, in the whole and refined wheat bread crust-like samples, FUR concentration was lower $(<100 \mathrm{mg} / \mathrm{kg})$ [29]. Moreover, highly significant negative correlations were found between FUR content and $p$-coumaric $(-0.97, p<0.05)$, catechin $(-0.94, p<0.05)$, rutin, gallic, ferulic, vanillic, and syringic acid $(-0.93, p<0.05)$ concentrations in the crumb and crust, indicating that they might be involved in the protein protection (Table 3).

Table 2. Formation of Maillard reaction products (MRPs) in buckwheat bread formulated with raw and roasted buckwheat flour.

\begin{tabular}{ccccc}
\hline \multirow{2}{*}{ MRPs } & \multicolumn{2}{c}{ Raw Buckwheat Bread } & \multicolumn{2}{c}{ Roasted Buckwheat Bread } \\
\cline { 2 - 5 } & Crumb & Crust & Crumb & Crust \\
\hline FUR (mg/kg) & $71.61 \pm 5.34^{\mathrm{b}}$ & $117.56 \pm 5.96^{\mathrm{a}}$ & $6.34 \pm 0.68^{\mathrm{c}}$ & $8.73 \pm 1.82^{\mathrm{c}}$ \\
FIC (FI/g) & $44.43 \pm 1.08^{\mathrm{b}}$ & $47.07 \pm 1.29^{\mathrm{b}}$ & $62.06 \pm 2.17^{\mathrm{a}}$ & $65.05 \pm 1.15^{\mathrm{a}}$ \\
CML (mg/kg) & $423.37 \pm 10.61^{\mathrm{c}}$ & $508.85 \pm 18.61^{\mathrm{b}}$ & $418.56 \pm 11.4^{\mathrm{c}}$ & $617.86 \pm 22.18^{\mathrm{a}}$ \\
\hline
\end{tabular}

Results are mean \pm standard deviation. Different letters $(a, b, c)$ in the same row mean significant differences $(p<0.05)$. FUR—furosine; FIC—fluorescent intermediate compounds; CML-N $\epsilon$-carboxymethyl lysine.

Table 3. Correlation coefficients between MRPs, phenolic compounds and antioxidant activity for raw and roasted buckwheat bread.

\begin{tabular}{|c|c|c|c|c|}
\hline & FUR & FIC & CML & TEAC \\
\hline FUR & & $-0.89 *$ & -0.16 & $0.99 *$ \\
\hline FIC & $-0.89 *$ & & 0.48 & $-0.85 *$ \\
\hline CML & -0.16 & 0.48 & & -0.05 \\
\hline TEAC & $0.99 *$ & $-0.85 *$ & -0.05 & \\
\hline 1-O-Sinapoyl-beta-D-glucose & -0.47 & $0.78 *$ & 0.50 & -0.41 \\
\hline 4-Hydroxybenzoate-O-glucoside & $0.79 *$ & $-0.96 *$ & -0.41 & $0.76^{*}$ \\
\hline 4-Hydroxybenzoic acid & $-0.93 *$ & $0.97 *$ & 0.26 & -0.91 * \\
\hline Caffeic acid & 0.83 * & $-0.99 *$ & -0.47 & $0.79 *$ \\
\hline Catechin & -0.94 * & $0.96^{*}$ & 0.24 & $-0.92 *$ \\
\hline Dihydroxybenzoic acid & $-0.93 *$ & $0.97 *$ & 0.25 & -0.91 * \\
\hline Ferulic acid & $-0.93 *$ & $0.99 *$ & 0.40 & -0.90 * \\
\hline Gallic acid & -0.93 * & 0.97 * & 0.27 & -0.91 * \\
\hline Naringenin & -0.93 * & $0.95 *$ & 0.20 & -0.91 * \\
\hline Quercetin & 0.94 * & $-0.98 *$ & -0.31 & $0.91 *$ \\
\hline Rutin & -0.93 * & $0.95 *$ & 0.21 & -0.91 * \\
\hline Syringic acid & -0.93 * & $0.99 *$ & 0.39 & -0.89 * \\
\hline Vanillic acid & $-0.93 *$ & $0.99 *$ & 0.38 & -0.90 * \\
\hline$p$-coumaric acid & $-0.97^{*}$ & 0.94 & 0.18 & $-0.96^{*}$ \\
\hline
\end{tabular}

* Correlation is significant $(p<0.05) ; \mathrm{n}=4$; FUR—furosine; FIC—fluorescent intermediate compounds; CML-N $\epsilon$ carboxymethyl lysine.

On the other hand, buckwheat bread samples formulated with roasted buckwheat flour showed a statistically significant increase in their levels of FIC. Surprisingly, there in the level of FIC were no statistically significant differences between the level of FIC in the crust and the crumb of the buckwheat bread prepared from the same kind of flour. This may suggest that different conditions during baking, such as temperature and water activity inside and on the surface of the dough, do not significantly affect the level of these intermediary MRPs [30]. 
The negative correlation coefficient $(-0.89, p<0.05)$ between FUR and FIC confirms that this nonenzymatic browning reaction in the bread samples tended towards the formation of intermediary and subsequently more advanced MRPs. This observation is in agreement with Carciochi et al. [31], who found significant increases in FIC level after roasting quinoa seeds, at $160{ }^{\circ} \mathrm{C}$ and $190{ }^{\circ} \mathrm{C}$ for 60 to $90 \mathrm{~min}$. It can further be assumed that a high concentration of quercetin in raw buckwheat flour markedly contribute to suppressing FIC formation $(-0.98, p<0.05)$. This is in line with the study of Zhang et al. [26] who reported that quercetin most strongly inhibits fluorescent AGEs in a cookie model, followed by naringenin, rosmarinic acid, and epicatechin.

One valuable marker for monitoring the progress of the Maillard reaction in food is $\mathrm{N} \epsilon$-carboxymethyl lysine (CML). The use of roasted buckwheat flour did not affect the CML content in the crumb obtained from raw buckwheat flour (Table 2). However, it should be emphasized that the process of roasting buckwheat grains increased $(21.42 \%)$ the CML content of the buckwheat bread crust. It is known that the temperature of the crust exceeds that of the crumb by over $100{ }^{\circ} \mathrm{C}$ [32]. Heat transmission during the baking process thus favors the formation of Maillard reaction products (MRPs) in the crust. Compared to the literature data, discrepancies can be seen between the CML content of bread prepared from buckwheat flour and the model wheat bread $(49.71 \mathrm{mg} / \mathrm{kg}$ bread and $15.09 \mathrm{mg} / \mathrm{kg}$ crumb) [13], as well as the model sponge cake prepared using a different type of sugar (1.16-6.64 $\mathrm{mg} / \mathrm{kg}$ model cake) [33]. Interestingly, no significant correlation was found between CML and phenolic compounds content in the bread crumb and crust, regardless of the type of flour used. It should be highlighted that flavonoids with the 3-OH and 5-OH groups in the A ring may have the ability to trap reactive dicarbonyl compounds and thus inhibit the formation of advanced glycation end products (AGE) [34]. Despite the fact that rutin is considered to have antioxidant properties, in this study we noted no inhibitory effects on the formation of AGE. Moreover, the inhibitory effect of phenolic compounds can not only be associated with a high concentration of rutin because other compounds could also be responsible for antagonistic or synergistic effects on Maillard reaction product formation [35]. Starowicz et al. [36] stated that supplementation with rutin of rye and buckwheat biscuits increased the formation of volatile compounds typical of the advanced stage of the Maillard reaction. It can thus be suggested that a high level of quercetin $3 \beta$-D-rutinoside (rutin) in the crumb and crust of roasted buckwheat bread can also be involved in the formation of increased concentrations of advanced MRPs in the bread samples. These findings agree with those of Yuan et al. [37], who reported that the type and concentration of natural antioxidants significantly affect the formation of Maillard reaction products. A higher concentration of phenolic compounds can also have a promoting effect on the formation pathway of advanced MRPs. Conversely, Przygodzka et al. [38] reported that the enrichment of rye and buckwheat ginger cakes formulated from rye flour and roasted dehulled buckwheat flour with $50 \mathrm{mg}$ and $100 \mathrm{mg}$ rutin, respectively, did not result in an increase in CML, i.e., $24.36 \mathrm{ug} / \mathrm{g}$ without rutin; $23-83 \mu \mathrm{g} / \mathrm{g}$ with $50 \mathrm{mg}$ of rutin, and 22-96 $\mu \mathrm{g} / \mathrm{g}$ with $100 \mathrm{mg}$ of rutin addition.

Principal component analysis (PCA) of the MRP and phenolic compound concentrations, as well as of the antioxidant activity of the samples was performed in order to identify the main factors determining the properties of the buckwheat bread (Figure 1). The two principal components (PCs) explained $96.93 \%$ of the total variance. The score plot (Figure 1a) shows a clear separation in the negative component of PC1 for the crumb and crust of the bread formulated with the roasted buckwheat flour, and in the positive scores of PC1 for the crumb and crust of the bread formulated with the raw buckwheat flour. This separation is related to the relative levels of FIC and CML the former being higher for the gluten-free bread made from roasted buckwheat flour than from raw buckwheat flour, the reverse being observed concerning FUR. Indeed, it was observed that CML and FIC were located in the negative PC1/negative compound of PC2, in the same area as the roasted buckwheat crust, but FUR was found in the area of raw buckwheat crust (Figure 1b). On the other hand, the crust and crumb were either prepared from roasted or raw buckwheat 
flour according to PC2, this separation being related to the higher levels of CML in the crust. It can clearly be seen that only phenolic compounds are found in the negative PC1/positive PC2 and positive PC1/positive PC2 quadrants, where the roasted and raw buckwheat bread crumb is located (Figure 1b). The phenolic compounds found in the area with the roasted and raw buckwheat breadcrumbs were 4-hydroxybenzoic acid (3), catechin (5), dihydroxybenzoic acid (6), gallic acid (8), naringenin (9), rutin (11), and $p$-coumaric acid, (14) as well as 1-O-sinapoyl-beta-D-glucose (1), ferulic acid (7), syringic acid (12), and vanillic acid (13).

a

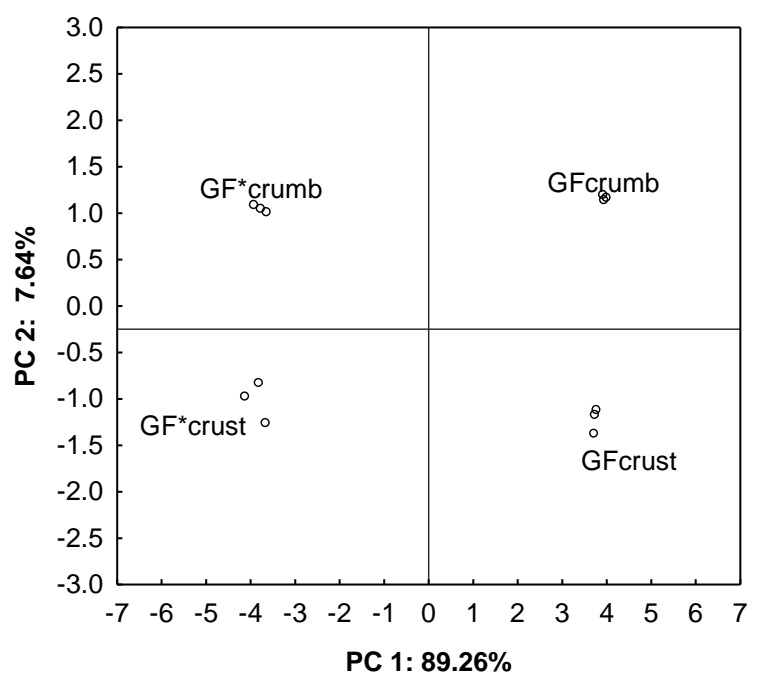

b



Figure 1. Principal component analysis (PCA) score plot (a): gluten-free (GF) crumb: GF bread crumb formulated with raw buckwheat flour; GF crust: GF bread crust formulated with raw buckwheat flour; GF* crumb: GF bread crumb formulated with roasted buckwheat flour; $\mathrm{GF}^{*}$ crust: GF bread crust formulated with roasted buckwheat flour; loading plot (b): 1 : 1-O-sinapoyl-beta-D-glucose; 2: 4-hydroxybenzoate-O-glucoside; 3: 4-hydroxybenzoic acid; 4: caffeic acid; 5: catechin, 6: dihydroxybenzoic acid; 7: ferulic acid; 8: gallic acid; 9: naringenin; 10: quercetin; 11: rutin; 12: syringic acid; 13: vanillic acid; 14: $p$-coumaric acid.

\section{Materials and Methods}

Raw and roasted buckwheat flour (Glutenex, Sady, Poland) from Polish commercial buckwheat (Fagopyrum esculentum Moench) were purchased from a local market. The producer confirmed that the carbohydrate, protein, and fat contents in the raw and roasted flour were: 63 and $69 \mathrm{~g} / 100 \mathrm{~g}, 13$ and $12 \mathrm{~g} / 100 \mathrm{~g}$, and 3.1 and $2.9 \mathrm{~g} / 100 \mathrm{~g}$, respectively.

\subsection{Bread-Making Process}

Samples of bread were prepared using $200 \mathrm{~g}$ of raw or roasted buckwheat flour, $3 \mathrm{~g}$ of salt, $18 \mathrm{~g}$ of sugar, $20 \mathrm{~g}$ of oil, $3 \mathrm{~g}$ of yeast, and $160 \mathrm{~g}$ of water, following the recipe of Pongjaruvat et al. [39]. All the ingredients were mixed together using a KitchenAid mixer (KitchenAid, Benton Harbor, MI, USA) for $8 \mathrm{~min}$ at a speed of $70 \mathrm{rpm}$. After $60 \mathrm{~min}$ of fermentation (at $35{ }^{\circ} \mathrm{C}$, with relative humidity $75 \%$ ), the dough was divided into two parts of equal weight, placed into baking forms, and proofed for $20 \mathrm{~min}$. The dough was then baked at $230^{\circ} \mathrm{C}$ for $35 \mathrm{~min}$ in an oven (MIWE Michael Wenz, Amstein, Germany) on a semitechnical scale. Afterward, the buckwheat bread was left at room temperature for 2 $\mathrm{h}$ to cool down and then sliced (about $1.5 \mathrm{~cm}$ thick). The crust and crumb were carefully separated and ground for later analysis.

\subsection{Extraction and Analysis of Polyphenolic Compounds}

A mixture of methanol, water, and formic acid (70:29.7:0.3 $v / v / v)$ was used to extract phenolic compounds from the buckwheat bread crumb and crust [40]. The compounds 
present in each sample were identified based on the retention time of standard and molecular mass and structural information from the MS detector during MS/MS experiments. Limit of quantification (LOQ where $S / N>15$ ) was determined for hydroxybenzoic acid, caffeic acid, catechin, dihydroxybenzoic acid, ferulic acid, gallic acid, naringenin, quercetin; syringic acid, vanillic acid, $p$-coumaric acid and it was not lower than $0.01 \mu \mathrm{g} / \mathrm{mL}$; LOQ for rutin was $0.05 \mu \mathrm{g} / \mathrm{mL}$. Sinapoyl glucoside and hydroxybenzoate glucoside were quantified as sinapic acid and 4-hydroxybenzoic acid, respectively. Calibration and quality control (QC) samples were prepared in methanol, water, and formic acid (70:29.7:0.3 v/v/v). Recovery of QC was higher than $93 \%$ and recovery of standards spiked to extracts of buckwheat bread crumb and crust samples was in the range $86-110 \%$. Carryover between injections was not observed. The coefficient of determination $\left(R^{2}\right)$ for all calibration curves was higher than 0.995 .

Analysis was performed using reversed-phase (C18 column) ultra-high performance liquid chromatography-electrospray ionization mass spectrometry (RP-UHPLC-ESI-MS, Dionex UltiMate 3000 UHPLC; Thermo Fisher Scientific, Sunnyvale, CA, USA), following the method described by Dziedzic et al. [41].

\subsection{Antioxidant Activity}

The same extracts obtained for the determination of polyphenolic compounds were used for the analysis of antioxidant activity. One gram of lyophilized and ground sample was extracted in $7 \mathrm{~mL}$ of an aqueous solution with $70 \%$ methanol, $29.7 \%$ water, and $0.3 \%$ formic acid and the extraction was carried out in a water bath at $70{ }^{\circ} \mathrm{C}$ for $45 \mathrm{~min}$ with mechanical shaking. The total antioxidant activity was measured using the ABTS radical (2,20-azinobis-(3-ethylbenzothiazoline-6-sulfonic acid)) following the method described by Re et al. [42]. The results were expressed in $\mu$ mols Trolox Equivalent Antioxidant Capacity (TEAC) per $1 \mathrm{~g}$ of dry matter of bread sample.

\subsection{Analysis of Maillard Reaction Products}

Furosine (2-furoylmethyl-lysine) was determined using the method described by Gökmen et al. [28]. The hydrolyzed sample was filtered through medium-grade filter paper and the diluted filtrate was passed through an Oasis HLB cartridge to remove any dark-colored interfering compounds before analysis with HPLC. A Waters Alliance HPLC System 600 (Milord, MA, USA) with a photodiode array detector was used. The furosine quantitation was based on a calibration curve by the external standard method (limit of detection (LOD) $5.75 \mathrm{ng} / \mathrm{mL}$; LOQ $11.93 \mathrm{ng} / \mathrm{mL}$ ). The results were expressed as $\mathrm{mg} / \mathrm{kg}$ of sample.

Free fluorescent intermediate compounds (FIC) were determined as described by Delgado-Andrade et al. [43] and measured at $\lambda \mathrm{Ex}=340$ and $\lambda \mathrm{Em}=420 \mathrm{~nm}$ using a fluorescence spectrophotometer (Shimadzu RF5001 PC, City, Japan). FIC data were expressed as mean values in fluorescence intensity (FI)/g sample.

CML (Ne (carboxymethyl)-L-lysine) was determined following the method described by Mildner-Szkudlarz et al. [25]. Following defatting, protein reduction, hydrolysis, and derivatization using o-phthaldialdehyde; CML determination was performed using a Waters Alliance HPLC system 600 (Milord, City, MA, USA) with a fluorescence detector (Waters 474). The compounds identified were quantified using the external standard calibration procedure. The limit of detection (LOD) was $0.42 \mathrm{ng}$, and the limit of quantification (LOQ) was $1.29 \mathrm{ng}$. The results were expressed as $\mathrm{mg} / \mathrm{kg}$ of sample.

\subsection{Statistical Analysis}

All analyses were carried out in triplicate $(n=3)$ for each sample. Tukey's honest significant difference multiple comparison (one-way ANOVA) at a $p<0.05$ level was performed and Pearson correlations were determined using Statistica 13 software (Dell Software, city, state abbr. USA). Principal component analysis (PCA) was performed using selected data from the analysis. The results are presented as a two-dimensional system 
(biplot) obtained by plotting the observations and variables on the plane formed of the calculated principal components.

\section{Conclusions}

This is the first study reporting the formation of Maillard reaction products in buckwheat bread produced using raw and roasted flour. Buckwheat bread-making not only affects the formation of compounds with antioxidant activity but also promotes potentially harmful Maillard reaction products including FUR, FIC, and CML. However, the results suggest that raw buckwheat flour is a more appropriate ingredient for the production of buckwheat bread because the application of roasted buckwheat flour led to a higher concentration of fluorescent intermediate compounds and also the advanced glycation products formation. Taking into account the possibility of reducing the formation of potentially toxic MRPs, further investigation, especially on the role of dicarbonyl compounds, is required to better understand the mechanism of the Maillard reaction in this type of food matrix.

Author Contributions: Conceptualization, M.B.R. and S.M.-S.; methodology, S.M.-S.; validation, A.S. (Aleksander Siger), A.S. (Artur Szwengiel); formal analysis, M.B.R. and A.S. (Artur Szwengiel); investigation, M.B.R.; data curation, M.B.R.; writing—original draft preparation, M.B.R.; K.D.; S.M.-S. writing - review and editing, S.M.-S.; supervision, S.M.-S. All authors have read and agreed to the published version of the manuscript.

Funding: This research was funded by the National Science Centre, Poland (Project No. 2017/27/N/N Z9/00905) and The APC was funded by Project No. 2017/27/N/NZ9/00905.

Institutional Review Board Statement: Not applicable.

Informed Consent Statement: Not applicable.

Data Availability Statement: The datasets generated during and/or analyzed during the current study are available from the corresponding author on reasonable request.

Conflicts of Interest: The authors declare no conflict of interest. The funders had no role in the design of the study; in the collection, analyses, or interpretation of data; in the writing of the manuscript, or in the decision to publish the results.

Sample Availability: Samples of bread are available from the corresponding author.

\section{References}

1. Cappelli, A.; Oliva, N.; Cini, E. A Systematic Review of Gluten-Free Dough and Bread: Dough Rheology, Bread Characteristics, and Improvement Strategies. Appl. Sci. 2020, 10, 6559. [CrossRef]

2. Rybicka, I. The Handbook of Minerals on a Gluten-Free Diet. Nutrients 2018, 10, 1683. [CrossRef]

3. Pacyński, M.; Wojtasiak, R.Z.; Mildner-Szkudlarz, S. Improving the aroma of gluten-free bread. LWT Food Sci. Technol. 2015, 63, 706-713. [CrossRef]

4. Martínez-Villaluenga, C.; Peñas, E.; Hernández-Ledesma, B. Pseudocereal grains: Nutritional value, health benefits and current applications for the development of gluten-free foods. Food Chem. Toxicol. 2020, 137, 111178. [CrossRef] [PubMed]

5. Dziedzic, K.; Szwengiel, A.; Górecka, D.; Rudzińska, M.; Korczak, J.; Walkowiak, J. The effect of processing on the phytosterol content in buckwheat groats and by-products. J. Cereal Sci. 2016, 69, 25-31. [CrossRef]

6. Liu, Y.; Cai, C.; Yao, Y.; Xu, B. Alteration of phenolic profiles and antioxidant capacities of common buckwheat and tartary buckwheat produced in China upon thermal processing. J. Sci. Food Agric. 2019, 99, 5565-5576. [CrossRef]

7. Zielinski, H.; Michalska, A.; Amigo-Benavent, M.; del Castillo, M.D.; Piskula, M.K. Changes in Protein Quality and Antioxidant Properties of Buckwheat Seeds and Groats Induced by Roasting. J. Agric. Food Chem. 2009, 57, 4771-4776. [CrossRef]

8. Małgorzata, W.; Konrad, P.M.; Zieliński, H. Effect of roasting time of buckwheat groats on the formation of Maillard reaction products and antioxidant capacity. Food Chem. 2016, 196, 355-358. [CrossRef]

9. Ma, Q.; Zhao, Y.; Wang, H.-L.; Li, J.; Yang, Q.-H.; Gao, L.-C.; Murat, T.; Feng, B.-L. Comparative study on the effects of buckwheat by roasting: Antioxidant properties, nutrients, pasting, and thermal properties. J. Cereal Sci. 2020, 95, 103041. [CrossRef]

10. Bhinder, S.; Singh, B.; Kaur, A.; Singh, N.; Kaur, M.; Kumari, S.; Yadav, M.P. Effect of infrared roasting on antioxidant activity, phenolic composition and Maillard reaction products of Tartary buckwheat varieties. Food Chem. 2019, 285, 240-251. [CrossRef]

11. Mesías, M.; Delgado-Andrade, C. Melanoidins as a potential functional food ingredient. Curr. Opin. Food Sci. 2017, 14, 37-42. [CrossRef] 
12. Berk, E.; Hamzalığlu, A.; Gökmen, V. Investigations on the Maillard Reaction in Sesame (Sesamum indicum L.) Seeds Induced by Roasting. J. Agric. Food Chem. 2019, 67, 4923-4930. [CrossRef] [PubMed]

13. Mildner-Szkudlarz, S.; Siger, A.; Szwengiel, A.; Przygoński, K.; Wojtowicz, E.; Zawirska-Wojtasiak, R. Phenolic compounds reduce formation of $\mathrm{N} \varepsilon$-(carboxymethyl)lysine and pyrazines formed by Maillard reactions in a model bread system. Food Chem. 2017, 231, 175-184. [CrossRef] [PubMed]

14. Kocadağlı, T.; Žilić, S.; Taş, N.G.; Vančetović, J.; Dodig, D.; Gökmen, V. Formation of $\alpha$-dicarbonyl compounds in cookies made from wheat, hull-less barley and colored corn and its relation with phenolic compounds, free amino acids and sugars. Eur. Food Res. Technol. 2016, 242, 51-60. [CrossRef]

15. Błaszczak, W.; Zielińska, D.; Zieliński, H.; Szawara-Nowak, D.; Fornal, J. Antioxidant Properties and Rutin Content of High Pressure-Treated Raw and Roasted Buckwheat Groats. Food Bioprocess Technol. 2013, 6, 92-100. [CrossRef]

16. Chandrasekara, N.; Shahidi, F. Effect of Roasting on Phenolic Content and Antioxidant Activities of Whole Cashew Nuts, Kernels, and Testa. J. Agric. Food Chem. 2011, 59, 5006-5014. [CrossRef] [PubMed]

17. Sakač, M.; Torbica, A.; Sedej, I.; Hadnađev, M. Influence of breadmaking on antioxidant capacity of gluten free breads based on rice and buckwheat flours. Food Res. Int. 2011, 44, 2806-2813. [CrossRef]

18. Wu, X.; Fu, G.; Li, R.; Li, Y.; Dong, B.; Liu, C. Effect of thermal processing for rutin preservation on the properties of phenolics \& starch in Tartary buckwheat achenes. Int. J. Biol. Macromol. 2020, 164, 1275-1283. [CrossRef]

19. Vogrinčič, M.; Timoracka, M.; Melichacova, S.; Vollmannova, A.; Kreft, I. Degradation of Rutin and Polyphenols during the Preparation of Tartary Buckwheat Bread. J. Agric. Food Chem. 2010, 58, 4883-4887. [CrossRef]

20. Şensoy, Í.; Rosen, R.T.; Ho, C.-T.; Karwe, M.V. Effect of processing on buckwheat phenolics and antioxidant activity. Food Chem. 2006, 99, 388-393. [CrossRef]

21. Tang, C.-H.; Peng, J.; Zhen, D.-W.; Chen, Z. Physicochemical and antioxidant properties of buckwheat (Fagopyrum esculentum Moench) protein hydrolysates. Food Chem. 2009, 115, 672-678. [CrossRef]

22. Horáková, L. Flavonoids in prevention of diseases with respect to modulation of Ca-pump function. Interdiscip. Toxicol. 2011, 4. [CrossRef]

23. Djilas, S.M.; Milić, B.L. Naturally Occurring Phenolic Compounds as Inhibitors of Free Radical Formation in the Maillard Reaction. In Maillard Reactions in Chemistry, Food and Health; Elsevier: Woodhead Publishing, Cambridge, 2005; pp. 75-81.

24. Kaur, C.; Kapoor, H.C. Antioxidants in fruits and vegetables-The millennium's health. Int. J. Food Sci. Technol. 2008, 36, 703-725. [CrossRef]

25. Mildner-Szkudlarz, S.; Siger, A.; Szwengiel, A.; Bajerska, J. Natural compounds from grape by-products enhance nutritive value and reduce formation of CML in model muffins. Food Chem. 2015, 172, 78-85. [CrossRef]

26. Zhang, X.; Chen, F.; Wang, M. Antioxidant and Antiglycation Activity of Selected Dietary Polyphenols in a Cookie Model. J. Agric. Food Chem. 2014, 62, 1643-1648. [CrossRef] [PubMed]

27. Wu, J.-W.; Hsieh, C.-L.; Wang, H.-Y.; Chen, H.-Y. Inhibitory effects of guava (Psidium guajava L.) leaf extracts and its active compounds on the glycation process of protein. Food Chem. 2009, 113, 78-84. [CrossRef]

28. Gökmen, V.; Serpen, A.; Açar, Ö.Ç.; Morales, F.J. Significance of furosine as heat-induced marker in cookies. J. Cereal Sci. 2008, 48, 843-847. [CrossRef]

29. Çelik, E.E.; Gökmen, V. Formation of Maillard reaction products in bread crust-like model system made of different whole cereal flours. Eur. Food Res. Technol. 2020, 246, 1207-1218. [CrossRef]

30. Thorvaldsson, K.; Skjöldebrand, C. Water Diffusion in Bread During Baking. LWT Food Sci. Technol. 1998, 31, 658-663. [CrossRef]

31. Carciochi, R.A.; D'Alessandro, L.G.; Manrique, G.D. Effect of roasting conditions on the antioxidant compounds of quinoa seeds. Int. J. Food Sci. Technol. 2016, 51, 1018-1025. [CrossRef]

32. Zhou, W.; Hui, Y.H.; De Leyn, I.; Pagani, M.A.; Rosell, C.M.; Selman, J.D.; Therdthai, N. Bakery Products Science and Technology; John Wiley \& Sons, Ltd.: Chichester, UK, 2014; ISBN 9781118792001.

33. Srey, C.; Hull, G.L.J.; Connolly, L.; Elliott, C.T.; del Castillo, M.D.; Ames, J.M. Effect of Inhibitor Compounds on N $\varepsilon$ (Carboxymethyl)lysine (CML) and N $\varepsilon$-(Carboxyethyl)lysine (CEL) Formation in Model Foods. J. Agric. Food Chem. 2010, 58, 12036-12041. [CrossRef] [PubMed]

34. Shao, X.; Bai, N.; He, K.; Ho, C.-T.; Yang, C.S.; Sang, S. Apple Polyphenols, Phloretin and Phloridzin: New Trapping Agents of Reactive Dicarbonyl Species. Chem. Res. Toxicol. 2008, 21, 2042-2050. [CrossRef] [PubMed]

35. Chompoo, J.; Upadhyay, A.; Kishimoto, W.; Makise, T.; Tawata, S. Advanced glycation end products inhibitors from Alpinia zerumbet rhizomes. Food Chem. 2011, 129, 709-715. [CrossRef] [PubMed]

36. Starowicz, M.; Koutsidis, G.; Zieliński, H. Determination of Antioxidant Capacity, Phenolics and Volatile Maillard Reaction Products in Rye-Buckwheat Biscuits Supplemented with 3ß-d-Rutinoside. Molecules 2019, 24, 982. [CrossRef]

37. Yuan, Y.; Shu, C.; Zhou, B.; Qi, X.; Xiang, J. Impact of selected additives on acrylamide formation in asparagine/sugar Maillard model systems. Food Res. Int. 2011, 44, 449-455. [CrossRef]

38. Przygodzka, M.; Zieliński, H. Characterization of the quality of novel rye-buckwheat ginger cakes by chemical markers and antioxidant capacity. Chem. Pap. 2016, 70. [CrossRef]

39. Pongjaruvat, W.; Methacanon, P.; Seetapan, N.; Fuongfuchat, A.; Gamonpilas, C. Influence of pregelatinised tapioca starch and transglutaminase on dough rheology and quality of gluten-free jasmine rice breads. Food Hydrocoll. 2014, 36, 143-150. [CrossRef]

40. Wang, R.; Zhou, W. Stability of Tea Catechins in the Breadmaking Process. J. Agric. Food Chem. 2004, 52, 8224-8229. [CrossRef] 
41. Dziedzic, K.; Górecka, D.; Szwengiel, A.; Sulewska, H.; Kreft, I.; Gujska, E.; Walkowiak, J. The Content of Dietary Fibre and Polyphenols in Morphological Parts of Buckwheat (Fagopyrum tataricum). Plant Foods Hum. Nutr. 2018, 73, 82-88. [CrossRef]

42. Re, R.; Pellegrini, N.; Proteggente, A.; Pannala, A.; Yang, M.; Rice-Evans, C. Antioxidant activity applying an improved ABTS radical cation decolorization assay. Free Radic. Biol. Med. 1999, 26, 1231-1237. [CrossRef]

43. Delgado-Andrade, C.; Rufián-Henares, J.A.; Morales, F.J. Study on fluorescence of Maillard reaction compounds in breakfast cereals. Mol. Nutr. Food Res. 2006, 50, 799-804. [CrossRef] [PubMed] 